\title{
Overcoming Social Inequality by Using Augmentative and Alternative Communication Devices in Education
}

\author{
Gezim Zeqiri ${ }^{1}$ \\ 1 Syracuse University \\ 900 South Crouse Ave, Syracuse, New York, 13244, USA
}

DOI: $10.22178 /$ pos.63-11

LCC Subject Category:

LB2300-2430

Received 14.09.2020

Accepted 28.10.2020

Published online 31.10 .2020

Corresponding Author:

gzeqiri@syr.edu

(C) 2020 The Author. This

article is licensed under a

Creative Commons

Attribution 4.0 License

(a) (1)

\begin{abstract}
For students whose different sorts of special needs restrict them to communicate with their peers, Alternative and Augmentative Communication (hereafter AAC) Devices have an important impact on overcoming social inequalities by facilitating communication, interactions, and learning outcomes. By interconnecting Assistive Technology with appropriate curriculum and methodology of teaching and learning, students with special communication needs may utilize AAC Devices and overcome some of the communication barriers they face.

The main purpose of this article is to research how the learning process occurs by implementing facilitated learning with the use of AAC Devices in United States schools, and its impact on student's ability to communicate efficiently and to interact with their peers, teachers, and so forth. In that context, the Article investigates how AAC Devices help students with communication disabilities to overcome communication inequalities and the way students can utilize them to be engaged in the learning process. To achieve this purpose, we have used participatory structured observation as the methodology of research.

We have visited one of the New York State Schools where AAC Devices were being used, and observed students' behavior and their learning outcomes while using those devices. Besides the facilitated learning by utilizing AAC devices, students with special communication needs were able to interact with their peers and teachers more effectively and express their opinions through those devices.
\end{abstract}

Keywords: education; inequality; communication; social interaction.

\section{INTRODUCTION}

Alternative and Augmentative Devices (hereinafter referred to as AAC devices) are considered as some of the most utilized tools that aim to improve people's lives and enhance their capabilities to efficiently communicate with others. It is estimated that "Over 49 million individuals in the United States present with an ongoing disabling condition. About 5.3\% of them, over 13 million people are users of assistive technology" [13]. Thus, the necessity of using these devices is immense, and researching this topic is considered of great importance. Having said that, many of such devices are being utilized in the learning environments such as Schools and Universities, to facilitate communication between students who communicate with difficulties or do not have any ability to communicate by other means.

However, there are various manners AAC devices are used in different learning environments. The efficacy and success rate of using those devices depend on many possible factors, such as the quality of Teacher's training received concerning AAC Devices, appropriate evaluation and determination of the specific devices to be used, appropriateness of the student's individual need for specific devices, and so forth.

In that context, the hypothesis that AAC Devices facilitate the learning process and social interaction of students with special communication needs will be proven by researching the impact of Augmentative and Alternative Communication Devices on the learning process and social interactions of students with special communication needs.

To find out the efficacy of communicating and learning by using AAC Devices, we have visited a learning environment where we have conducted several observations of students using such devices. Based on these observations, we could research the impact these devices have on a student's social life and their importance in the learning process. 


\section{METHODS}

The methodology of research used for this article is the qualitative method of participatory observation. We have been present in one of the Middle Schools in New York State to observe how AAC Devices were being used to facilitate the communication process and boost the learning efficacy of students with special needs.

The observation occurred with a pre-defined schedule and objectives. In that context, we had the full consent of research participants such as teachers and teacher assistants, who informed students in advance about my visits and the purpose of my research.

Data collected during observations were written and analyzed, later on, to focus on students' behavior and attitude towards AAC Devices. Then, after data analysis collected with participatory observation, we gave our suggestions to the school in terms of improving the effectiveness of using AAC Devices in the learning environment. Moreover, we have also suggested improvements that could be useful regarding a lesson plan, by providing a sample of good practices that could be utilized in the observed classroom and similar cases.

Due to confidentiality and the respect for the privacy of the observed students, we did not reveal the name of the school, nor the city where the research took place.

\section{LITERATURE REVIEW}

Communication is defined as the process of sharing information and ideas. "Communication can be successfully achieved through communicative functions such as seeking social interactions, making requests, and negations of an object or social interactions" [7]. To be able to effectively communicate, people with special communication needs may need the help of Assistive Technology (hereinafter referred to as AT). In general, most of the authors agree that AT, and in particular the AAC devices have an important impact on facilitating communication between people. Moreover, students identified as using AT had an average of seven devices listed on their Individual Education Plans (IEPs) and for many of these students, one of the devices was AAC (44.7\%) [11]. Thus, many authors' have tried to investigate this issue and find better ways of using those devices.

However, despite general agreement on the benefits of using AAC devices in a classroom, there is a lack of implementation support. "Although a school district receives federal funds to provide special education, there is not a separate federal fund allocated specifically for the provision of AAC devices and services" [6]. In that context, considering the benefits and the importance of such devices in the lives of students with special needs, more financial support is necessary to make a positive impact and develop a society of equality and inclusiveness where everyone can communicate effectively.

"Three recent systematic reviews concluded interventions involving aided AAC modeling can improve students' expressive and receptive communication skills" [1]. This is particularly important when having in mind the large number of people who need such devices to be able to communicate with others. Particularly, a large number of students with special needs utilize AAC devices to learn and communicate with their peers and teachers. "In other words, approximately $3 \%$ of all students with a disability utilize AAC" [3].

However, only the fact that there is a need for AAC devices or the fact those devices are extensively used among people with special needs does not guarantee successful and effective communication. "Successful communication using AAC devices largely depends on the function of the technology, the severity of the individuals' disabilities with regards to their physical, sensory, and cognitive functions" [9].

Thus, beyond communication as a way to express one's thoughts, effective communication in an inclusive classroom or school setting would be also beneficial in terms of student's socialization and their feeling of belonging. For that, "...peer network interventions involving aided AAC modeling can be effective to improve the symbolic communication of students with complex communication needs while enhancing their social experiences with peers within inclusive school settings" [2]. In that context, it is of great importance to have twoway communication between peers, meaning that all students involved in that kind of communication should be able to understand the principles of using AAC devices. "Teaching peers to use aided AAC as a shared means of communication could demonstrate the device is a useful mode of communication and help students build connections between the meaning of spoken words, graphic symbols, and their referents [10]. In other words, "establishing the effectiveness of assistive technology devices, however, is no guarantee that they 
will be routinely used by either practitioners or parents with young children with disabilities" [14]. Other obstacles could prevent the overall success of AAC devices, despite the technical efficacy and functionality of those devices. "One of these is the failure to use evidence-based training methods to promote practitioners' and parents' understanding of and skills in using different types of assistive technology devices" [5]. Thus, when deciding to utilize AAC devices, it is necessary to consider the most proper methodology, training, and appropriateness of the device based on each student.

\section{RESULTS}

The participatory observation that was done in a special education classroom was divided into two equal parts. In the first part, I have observed Eric, one of the autistic students who went through several surgeries and other difficulties, and during the second part of the observation, I was focused on another autistic student named Je. Of course, I couldn't avoid observing all other students from time to time, but I made efforts to focus my observation on these two students.

The classroom had 12 students, and all of them were diagnosed with some kind of disability. For every three students, an assistant teacher was assigned to work closely with them. In that context, the classroom had 1 main teacher and 3 regular assistant teachers.

The purpose of the observation was to find out how AAC devices were being used in this school, and what benefits they brought up to students with special communication needs, and their social interactions with the rest of the class participants. Put in another way, the impact of AAC devices on the observed students' lives and the learning process facilitated by using AAC devices were the aim of this research project.

\section{1st part of the Classroom Observation}

Students' name: Eric. When I came to the School, my first contact was MS T. Kogut who was informed about my visit and the purpose of the research. She introduced me to the main teacher of the target classroom, Ms. Moskow, and briefly informed me in detail about each of the students' conditions and what their special needs are. Other assistant teachers were: Jim, Daron, Chris, and a health attendant Gene.
The classroom was composed of:

2 autistic children - Eric and Ji (which I have observed in detail);

2 paralyzed girls - one of them also had a mental deficiency and the other one had cerebral palsy;

1 asocial girl - Janiah

1 mild mental deficient - John

1 mentally deficient, but very social girl - Jaylin.

The first student I had observed - Eric, a 15-yearold boy, was diagnosed with an autism spectrum disorder. According to many authors, people with this condition often need some kind of facilitation to develop communication abilities. "Individuals with autism typically display inefficiencies in communication. With increasing numbers of children being diagnosed with Autism Spectrum Disorder, it is necessary to find effective methods of communication for these children. Augmentative and alternative communication interventions develop communication skills using unconventional techniques" [8].

Earlier in his life, Eric experienced severe seizures and went through brain surgery to ease those seizures. The surgery affected his intellectual capacities, so now he also suffers from intellectual deficiency, which further affected his ability to communicate with others.

Having said that, according to Cook, "a core characteristic of children with Autism Spectrum Disorder (ASD) is their atypical development of social skills, language, and communication" [12]. Thus, it is important to improve conditions that may facilitate the development of these skills by using some sort of Assistive Technology. "If a child with ASD can be taught to communicate, more learning opportunities can take place. One way of teaching communication has been through the use of Augmentative and Alternative Communication (AAC)" [12].

Returning to Eric, he is usually quiet and sustained in most of the learning processes and social situations inside the classroom. He keeps calm most of the time, although as some of the class teachers informed me, from time to time Eric displayed some kind of aggressive behavior. According to his teachers, one of the possible reasons for this behavior is, for instance, the absence of his teachers with whom he feels closer. Otherwise, most of the time he stands quiet and rarely makes any noise. 
Eric is not communicative and cannot spell any words. He uses some sort of sign language, and he can respond by saying "ah" for everything. Eric uses the "Augmentative and Alternative Communication Schedule Board" - a device that appears too simple and has a lack of options. It has only a little space to put pictures - (usually the teacher puts only two pictures), and Eric is provided with two options to choose from. When Eric points to and makes physical contact with the correct picture, his teachers give him positive feedback/motivation what reinforces his response. In other words, the teacher puts two different pictures in each space and usually goes near the student by asking which one is correct. For instance, two pictures that were often put in the device for Eric contained: Wednesday and Tuesday. The teacher asked Eric what day is today, and he had to respond by touching one of the buttons. Then, the teacher changed the pictures and put something else on the board. Most of the time, Eric responded to the given tasks and touched the correct picture. Whenever he guessed the correct option, all teachers encouraged him by saying: good job Eric, well done, and so forth. In that context, they have reinforced his behavior by giving him a social reward for the correct answer.

Eric is asocial to some extent, but he shows some signs of being engaged in classroom activities. When students went to the gym for a physical education class, he played with a ball chair and stayed near other children. At the time he wasn't playing, he sat down and watched other children playing.

In general, the device used in this case was too limited and could not do much for its users. It was only used in a morning "calendar \& schedule" activity, and after that, the printed hand-outs were used more often. Thus, our recommendation would be to use AAC devices more often and in several activities during the whole day. If possible, I strongly recommend to the school administration to explore the possibility of purchasing other more advanced AAC devices, which would provide more support for Eric and other students as well. Since every student in that classroom, except John, cannot communicate by speaking, an I-pad or a chin-switch (for cerebral palsy) would make a difference in these children's life.

\section{2nd part of the Classroom Observation}

Students' name: Ji. Ji is another student I have focused on during the second part of my observation. He is 13 years old and similarly to Eric, was diagnosed with an autistic spectrum disorder. He also has intellectual deficiency and a condition called echolalia which makes him repeat words too often.

Ji is usually quiet and calm. He wears some large headphones and appears to enjoy the music. Although at the time I was observing, his headphones had some kind of defect and there was no music playing, he kept wearing them and even pretended he is dancing with the music rhythm. He moved his hands in a way that indicated following a certain rhythm.

On the other hand, in a gymnastics class, there was real music playing in the background, which made Ji look happy and dancing most of the time. He did not approach other students and wasn't interested in playing with them at all, not even with a ball chair (as Eric did). Ji also wears a green backpack, but I could not find out the reason for that.

Ji can't speak or communicate with others. He uses the AAC device described in Eric's case. Except for the "schedule board" and a projector, no other AAC device was used during the whole time. However, Ji can use an unaided communication system to some degree, such as sign language.

Except for the schedule board mentioned above, in many cases was also utilized a Projector to display different content, for instance, CNN news, stories, and so forth, but Ji showed no interest whatsoever. In my opinion, the projector could be utilized better by presenting more age-appropriate clips, because the daily news seemed not to evoke any interest in most of the student's minds.

\section{Other Observations}

While staying at the School, except for the assigned students, I couldn't avoid observing others too. In particular, I noticed some interesting events by observing the behavior of John and Jailyn.

According to most of the teachers, and also based on my observation, John was the only student who could speak and make sense in a conversation. Compared to other classmates, he seems to be mildly affected by intellectual deficiency and is fully body-abled. He is very social and approaches 
every teacher, student, and even approached and tried to include me in some of the conversations. He could do most of the assigned tasks and even realized what words form a rhyme (most of the time).

Since John was the only one who could speak, in my point of view he gained more attention than other students. For that reason, I would strongly suggest the school to purchase more AAC devices which would enable other non-speaking students to communicate all the time. Even more scheduleboards-alike devices or a switch would be beneficial in some cases when yes/no questions were asked.

On the other hand, Jailyn was a girl with intellectual deficiency who showed a social attitude and a great interest to explore people and devices. She was particularly interested in watches and clothes design. She explored my watch several times and seemed to be enthusiastic about it. In contrast, she showed no interest in smartphones, which made me think she is not interested in the things she already recognizes. By because Jaylin can't speak, and having in mind her curiosity to explore, I think she would be also interested in AAC devices. Advanced AAC devices with a lot of options and features would make it possible to change or add new icons, buttons, pictures, and so on, which would keep her curiosity ongoing.

The main purpose of this article was to research the impact of using AAC devices in the learning process of students with special communication needs. We have done this by visiting a school in New York State and observing the learning process by being present in the classroom.

We have identified strong and weak points of the methodology of teaching that was being implemented in the above-mentioned school. Likewise, we have analyzed student's reaction to various AAC devices used and suggested other kinds of devices which could be helpful in those particular cases and individually for each of the special need's students.

Based on observations done, we have developed and proposed improved lesson plans as an illustration of our suggestions being implemented in the future. In that manner, we have given our practical contribution to the school where the research was conducted, and hopefully, our suggestions have been delivered in other nearby schools as well.
However, the research conducted for this Article has its limitations and further investigation is much needed. Broader and continuous research that would include more than one particular school would give us more representative information. Likewise, it would be interesting to research schools that have recently received AAC devices and started implementing facilitated learning. That way, it would be possible to compare situations "with versus without" AAC devices and measure the impact of those devices in the learning outcome.

\section{CONCLUSIONS}

Based on participatory observation done at the special education classroom, it is obvious that AAC devices have a positive impact on the learning process of students with special communication needs, meaning that our hypothesis was confirmed. It is also possible to claim that the social life of students who have communication difficulties can be improved by the facilitation which AAC devices make possible.

However, as we have identified some of the weak points of our research in the discussion section, to provide a more representative sample, it is necessary to broaden the research and extend it to other schools and even other countries as well. Thus, I consider these case studies observed for this Article as a starting point that may lead to further research in the future.

Finally, this article has achieved its purpose by researching the learning process that occurred with utilizing various Augmentative and Alternative Communication devices, and its impact on student's social life, particularly on their ability to communicate efficiently with their peers and teachers. This way, we have analyzed how specific AAC devices impact the learning process individually and what can be done to improve learning efficiency. By doing this, we gave our contribution to a great cause such as researching more effective ways of communication in a classroom with students with special communication needs.

\section{RECOMMENDATIONS}

Schools should consider purchasing more AAC devices or make low-tech boards for each student. This way, all non-speaking students would be able to answer instantly (for instance yes/no questions). 
An I-pad would replace hand-outs and engage all students in every activity.

Make an Eye-Gaze Board for a girl with Cerebral Palsy. This simple and inexpensive board would enable her to communicate by staring at the provided pictures or words.

Buy an AAC Spinner (or make it) which could help the other paraplegic girl to be engaged in-class activities, i.e. in the gym she could spin pictures and choose with who and with which ball she likes to play.

AAC devices such as the I-pad would be beneficial in utilizing Jaylin's curiosity to explore new devices and would enable her to communicate better with the rest of the class.

Replace the content shown by a projector with more age-appropriate clips, to evoke students' interest and curiosity.

Consider moving some of the students to other general education classes, at least for some hours during the week. That way, they would learn more efficiently and expand their experience.

\section{DECLARATION OF CONFLICTING INTERESTS}

The author declared no potential conflicts of interest to the research, authorship, and/or publication of this article.

\section{Annex: Lesson Plan Improvement (Sample)}

Physical Education Plan for a class with special needs students

The classroom is composed of 12 students with different special needs. Some of the students are diagnosed with an autism spectrum disorder, and most of them have some intellectual deficiency. Most of the students are non-speakers, and they only use some sign language. They use a two-option button device to answer some questions.

Based on their different abilities and diagnosis, students need different AAC devices. For instance, the girl with cerebral palsy needs an Eye-gaze board or a switch that could be moved with her head. Other non-speaking students who have some social abilities would need I-pads where they would use a digital board to communicate with the class participants.

In the physical education class, I saw some interesting elements. Some of the students were playing with a ball, some with a spinning-rope, some others by walking, or by driving a wheelchair.

In the same class, I would like to see the following modifications:

- All students would utilize their own AAC devices to communicate. They would be able to express their needs and their wishes to walk with someone, to move, to play with someone they like, to dance, and so forth;

- The switch would have to be installed in a wheelchair of a cerebral palsy girl, so it can be used any time;

- In the case of another girl who uses a wheelchair, I suggest using an AAC Spinner - which would let her spin pictures of the games, students to play with, and so on;

This would make the class more interesting to her and enable her to interact with her classmates. Other AAC devices would be carried by the students or by the teachers in case it is assumed they would be damaged during the games.

The Physical Education class would be successful when all students would participate in any kind of activities they like in that class. By using a variety of AAC devices, this objective would have more chance to be fulfilled.

\section{REFERENCES}

1. Allen, A. A., Schlosser, R. W., Brock, K. L., \& Shane, H. C. (2017). The effectiveness of aided augmented input techniques for persons with developmental disabilities: a systematic review. Augmentative and Alternative Communication, 33(3), 149-159. doi: 10.1080/07434618.2017.1338752

2. Biggs, E. E., Carter, E. W., Bumble, J. L., Barnes, K., \& Mazur, E. L. (2018). Enhancing Peer Network Interventions for Students with Complex Communication Needs. Exceptional Children, 85(1), 6685. doi: 10.1177/0014402918792899

3. Blackorby, J., Wagner, M., Marder, C., \& Guzman, A. (2004). Student accommodations and supports, Retrieved from https://www.seels.net/designdocs/SEELS_W1C4_Ch7_Accom_042204final.pdf 
4. Cook, R. E., Klein, M. D., Tessier, A., \& Daley, S. E. (2003). Adapting early childhood curricula for children in inclusive settings. Princeton: Recording for the Blind \& Dyslexic.

5. Dunst, C. J., Trivette, C. M., Hamby, D. W., \& Simkus, A. (2013). Systematic Review of Studies Promoting the Use of Assistive Technology Devices by Young Children with Disabilities. Practical Evaluation Reports, 5(1), 1-32

6. Glennen, S., \& DeCoste, D. C. (1997). The handbook of augmentative and alternative communication. Australia: Thomson/Delmar Learning.

7. Hallahan, D. P., Kauffman, J. M., Pullen, P. C., \& Hallahan, D. P. (2009). Cases for reflection and analysis for Exceptional learners: An introduction to special education. Boston, Mass: Pearson Education.

8. Murray, J. (2014). Using Augmentative and Alternative Communication Interventions to Increase Functional Communication for Children with Autism Spectrum Disorder. BU Journal of Graduate Studies in Education, 6(2), 56-59.

9. Rasid, N., \& Nonis, K. (2015). Exploring communication technology behaviour of adolescents with cerebral palsy in Singapore. International Journal of Special Education, 30(3), 17-38.

10. Romski, M. A., \& Sevcik, R. A. (1998). Breaking the speech barrier: Language development through augmented means. Baltimore: P.H. Brookes.

11. Stegall, B. (2007). Status of assistive technology use in schools: Who, what, and where (Doctoral thesis); George Mason University.

12. Talkington, N., McLaughlin, T. F., Derby, K. M., ... Clark, A. (2013). Using an Augmentative and Alternative Communication Device to Teach a Preschooler with Developmental Delays to Request Assistance and Seek Attention. i-Manager's Journal on School Educational Technology, 8(4), 16-21. doi: 10.26634/jsch.8.4.2247

13. Wendt, 0. (2011). Assistive Technology: Principles and Applications for Communication Disorders and Special Education. N. d.: Brill. doi: 10.1163/9781780522951

14. Wessels, R., Dijcks, B., Soede, M., Gelderblom, G. J., \& De Witte, L. (2004). Non-use of provided assistive technology devices, a literature overview. Technology and Disability, 15(4), 231-238. doi: 10.3233/tad-2003-15404 